\title{
DESIGN AND TOOL ANCHORING FOR A 120-KILONEWTON EXPANDER CYCLE ROCKET ENGINE LIQUID OXYGEN TURBOPUMP
}

\author{
L. Souverein, C. Maeding, T. Aichner, B. Ivancic, \\ A. Wagner, and M. Frey \\ Airbus DS GmbH \\ Munich 81633, Germany
}

\begin{abstract}
As part of a German nationally funded research programme "TARES," a turbopump initiative has been started in recent years within Airbus DS GmbH. The aim of this study is to design a liquid oxygen (LOx) turbopump assembly (LOx-TPA) for a 120-kilonewton thrust class expander cycle rocket engine. To realize this objective, Airbus DS GmbH builds on in-house heritage, notably the turbopumps of the P111 and the H20 staged combustion engines. This experience serves as input for the design of the 120-kilonewton LOx turbopump. The current paper details the fluidic design of the turbopump, including the design philosophy and the anchoring on the heritage hardware. Discussed are the pump and turbine predesign starting from the configuration trade-off, the preliminary design, the flow path and blade design, and the design of inlet/outlet and the volute. Finally, the performance (nominal and off-design) is characterized by means of three-dimensional (3D) computational fluid dynamics (CFD) simulations.
\end{abstract}

\section{INTRODUCTION}

In recent years, a turbopump initiative has been started at Airbus DS GmbH as a part of a German nationally funded research programme "TARES." The study is aimed at the design of an LOx-TPA for a 120-kilonewton thrust class expander cycle rocket engine. To achieve this objective, a turbopump design process has been established, building on available software packages and capabilities with the acquisition of additional options and packages wherever necessary. For the anchoring of the design and simulation tools, Airbus DS GmbH draws on in-house heritage, notably the turbopumps of the P111 and the H20 staged combustion engines. Available design and test data have been used, with a focus on the

(C) The Authors, published by EDP Sciences. This is an open access article distributed under the terms of the Creative Commons Attribution License 4.0 (http://creativecommons.org/licenses/by/4.0/). 
redesign of the heritage hardware based on existing construction drawings and the original hardware itself. The CFD simulation results of the P111 axial turbine were compared to available historic data in terms of performance and studies have been initiated to recharacterize the $\mathrm{H} 2 \mathrm{O} \mathrm{LOx}$ inducer, both numerically and experimentally.

This experience serves as input for the design of the 120-kilonewton LOx turbopump. A trade-off has been performed [1] to define different configurations of the LOx-TPA, evaluating several alternatives to establish the most promising baseline design variant. Criteria include the pump and turbine efficiency, the cavitation margin, and the number of turbine stages. The selected baseline turbopump design consists of a high head inducer, radial impeller, and vaned diffuser on the pump side driven by a single stage subsonic axial turbine on the same shaft.

The paper details the fluidic design of the turbopump, including the design philosophy and the anchoring on the heritage hardware. Discussed are,

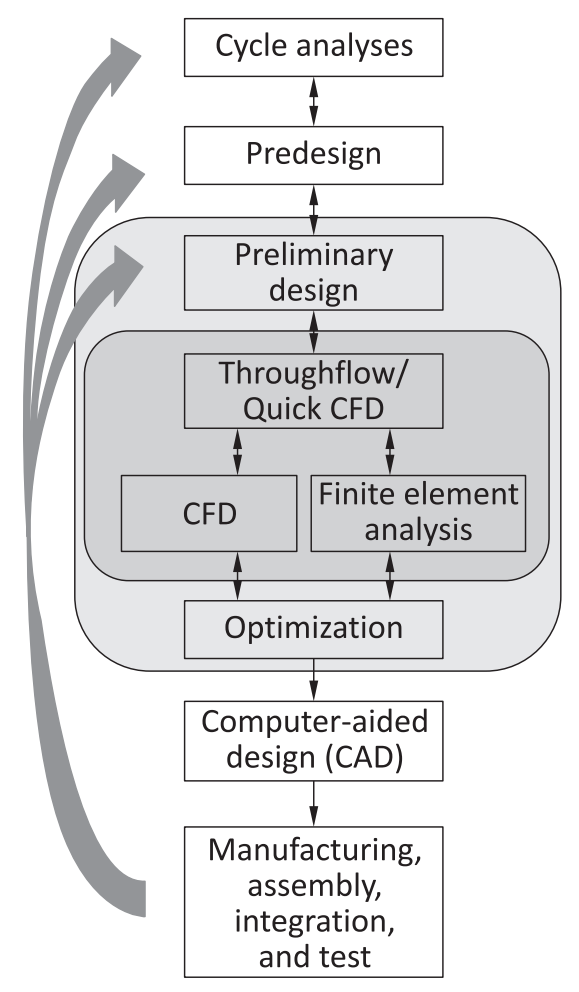

Figure 1 Established turbopump design work flow with the trade-off in [1] as starting point, the preliminary design based on one-dimensional (1D) theory and semiempirical correlations (inlet/ outlet diameters, blade heights, number of blades, efficiency estimate, and cavitation characteristics), the flow path and blade design (twodimensional design of meridian contour, blade mean lines, and blade profiling), and the design of inlet/outlet and volute. Finally, the performance (nominal and off-design) has been characterized by means of $3 \mathrm{D}$ CFD simulations and the suction performance of the inducer is characterized experimentally.

\section{DESIGN PROCESS}

As a part of the "TARES" research program, one of the principal aims of the current initiative within Airbus DS GmbH has been to establish the turbopump design process for the development (Fig. 1), with the aim of de- 
veloping a 120-kilonewton LOx-turbopump. The design flow builds largely upon available software packages and capabilities. The design process has now been established by means of anchoring on available heritage hardware data and a full design loop for the 120-kilonewton LOx-turbopump including manufacturing and testing for the inducer hardware.

\section{ANCHORING ON HERITAGE DATA}

To anchor the design process that has been established as a part of the TARES research program, Airbus DS GmbH has drawn on its turbopump heritage. Most notably, the $\mathrm{H} 2 \mathrm{O}$ 200-kilonewton and the P111 50-kilonewton stage combustion engines have been used as validation cases, for which detailed design and test data are available [1].

\subsection{Water and Liquid Oxygen - Turbopump Inducer}

The first case for anchoring the design tools was the H2O LOx-inducer from the 200-kilonewton $\mathrm{H}_{2} / \mathrm{O}_{2}$ staged combustion engine developed in Ottobrunn in the late 1960s and early 1970s for the Europa III rocket. Design and test reports are available from this period, documenting the thorough characterizations that were made on this inducer, including parameter studies concerning different geometrical properties. The tests were performed in both water and LOx at rotational speeds between 20000 and 40000 rotations per minute (rpm), the latter being the nominal value for the LOx-pump. Table 1 shows the nominal inducer characteristics. The relevant quantities are defined as follows:

$$
N_{\mathrm{SS}}=\frac{N \sqrt{Q}}{\mathrm{NPSHR}^{0.75}} ; \quad N_{s}=\frac{N \sqrt{Q}}{(\Delta H)^{0.75}} ; \quad \Phi=\frac{C_{m}}{U} ; \Psi=\frac{2 \Delta P}{\rho U^{2}}
$$

with the specific speeds being defined using the units $\mathrm{rpm}, \mathrm{m}^{3} / \mathrm{s}$, and $\mathrm{m}$ for, respectively, the rotational speed, the volumetric flow rate, and the head.

Table 1 Original test data for the $\mathrm{H} 2 \mathrm{O}$ inconel LOx inducer

\begin{tabular}{lc}
\hline \multicolumn{1}{c}{ Parameter } & Value \\
\hline Fluid & LOx \\
Rotation rate, $N$ & $40000 \mathrm{rpm}$ \\
Inlet flow coefficient, $\Phi_{\text {ind,in }}$ & 0.067 \\
Head coefficient, $\Psi_{\text {ind }}$ & 0.075 \\
Suction specific speed, $N_{\text {SS }}$ & 886 \\
Net positive suction pressure required, NPSPR & $2.2 \mathrm{bar}$ \\
\hline
\end{tabular}




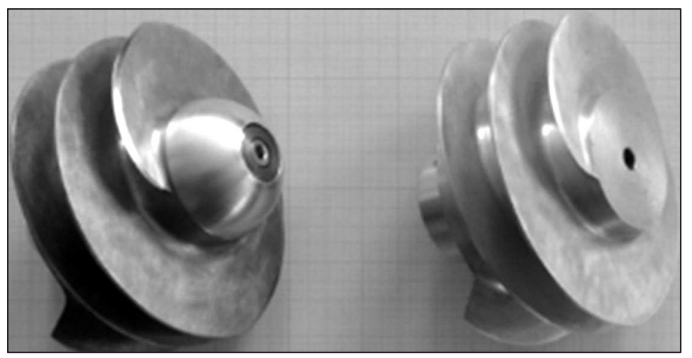

(a)

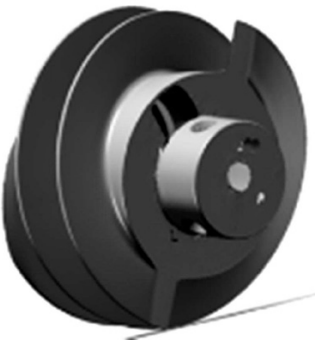

(b)

Figure 2 The H2O LOx inducer; original test hardware: $(a)$ inconel and aluminum; and $(b) 3 \mathrm{D}$-scan
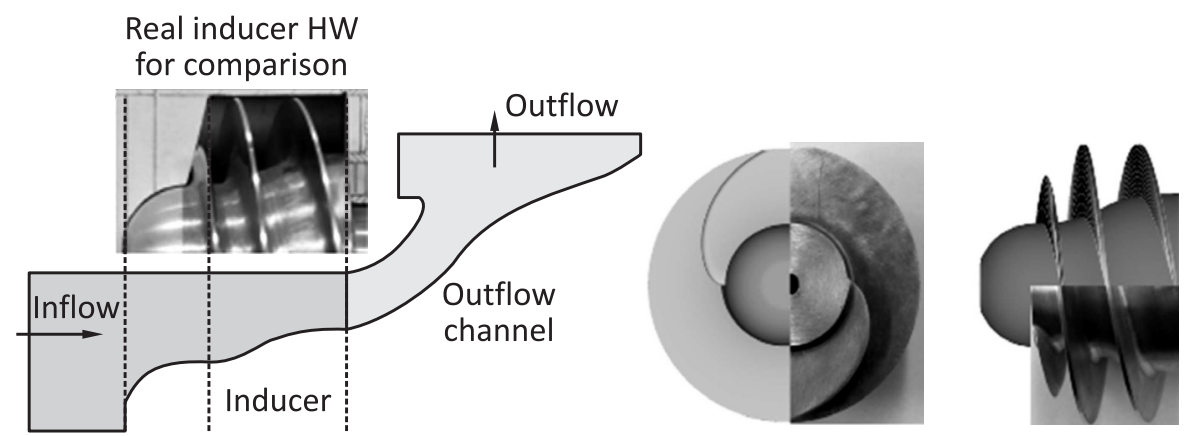

Figure 3 The H2O LOx inducer; redesign of original hardware for CFD-validation

The original hardware is still available today and has recently been scanned as input for 3D-CFD simulations (Fig. 2). The existing hardware and design data have served as a basis for the current redesign of the inducer (Fig. 3). In addition to an anchoring of the design tool, it serves as a basis for further CFD investigations, in particular, for cavitation modeling studies. These were undertaken by the DLR Göttingen in the context of the Propulsion2020 cooperation. In addition, the original inducer hardware has been recharacterized in a test campaign at the University of Kaiserslautern.

\subsection{P111 Axial Turbine}

The P111 LOx/kerosene 50-kilonewton staged combustion engine, developed in the 1960s in Ottobrunn, was chosen as the second anchoring case for the design tools. In particular, the single stage reaction turbine, driven by an oxygen rich 

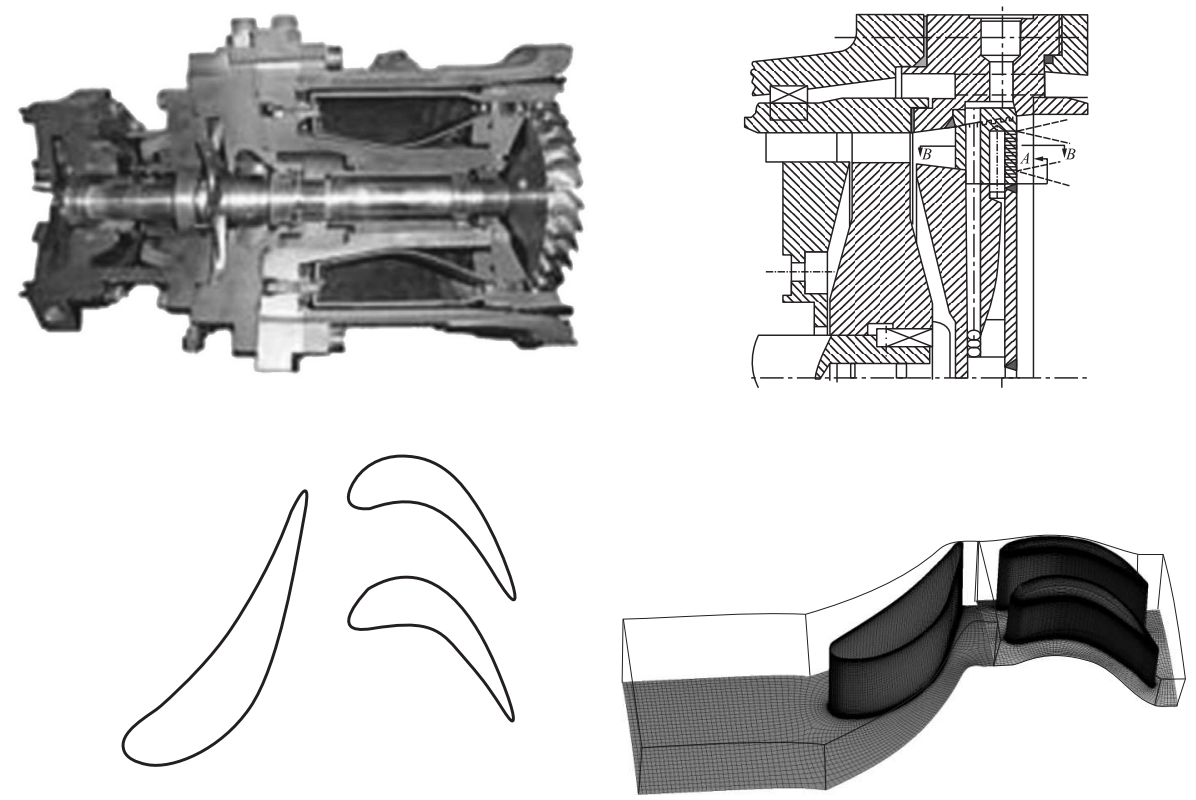

Figure 4 P111 original and redesigned (CFD-mesh) axial turbine geometry

preburner, was a valuable validation case. The original hardware, including design and test documentation, is available and has served as input for the redesign (using the original geometry) and the 3D CFD simulations.

The original P111 power-pack hardware, an excerpt of the construction drawing of the axial turbine, and the blade profiles are shown in Fig. 4. The figure also shows (at the bottom right) the numerical mesh used for the 3D CFD simulations of the redesign of the P111 axial turbines. The computational grid has a total size of $\sim 1.4$ million cells. It is divided into two domains: the stator domain with 500000 cells and the rotor domain with 900000 cells, both resolving a single blade. The applied wall resolution is $y^{+}=100$ using wall functions to estimate the viscous losses. The appropriate periodic boundary conditions were used to represent the complete turbine behavior. The CFD results are shown in Fig. 5, depicting the static pressure field normalized by the total inlet pressure (Fig. 5a) and displaying the relative Mach field (Fig. 5b). Shown are for both fields a blade-to-blade view generated at a relative blade span of 0.5 (top figures) and a mass weighted meridional view (bottom figures).

The performance results from the $3 \mathrm{D}$ CFD simulation are compared to the heritage hardware data in Table 2. The original efficiency has been determined from the test data. To enable a proper comparison with the current simulation results, the mechanical losses and the disk friction losses have been corrected 

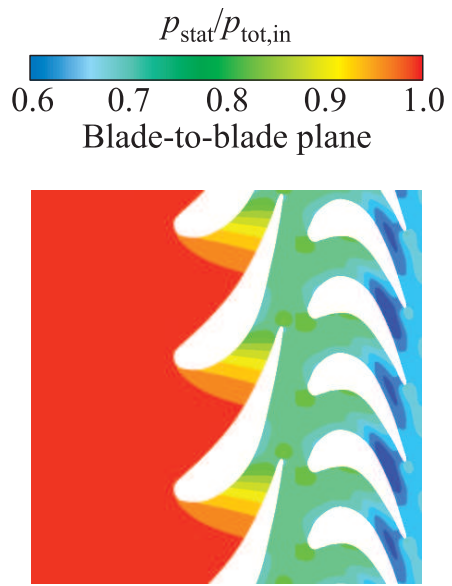

Meridional plane

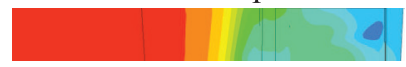

(a)
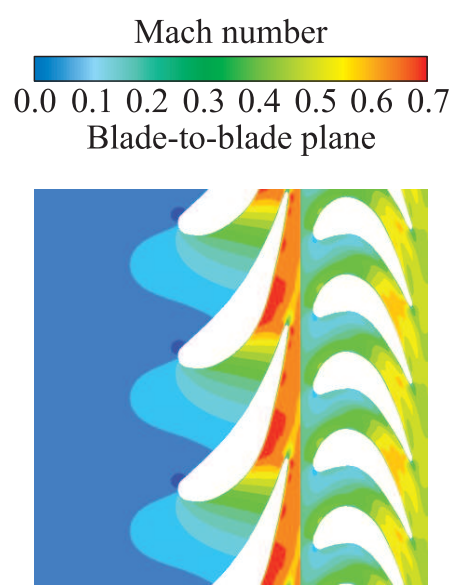

Meridional plane

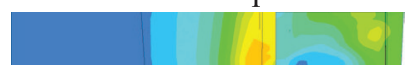

(b)

Figure 5 The 3D CFD results for the P111 axial turbine: (a) pressure ratio; and (b) relative Mach number

Table 2 P111 axial turbine characteristics compared with CFD results

\begin{tabular}{lc}
\hline \multicolumn{1}{c}{ Parameter } & Value \\
\hline \multicolumn{2}{c}{ Original hardware: Nominal characteristics } \\
\hline Rotation rate, $N$ & $25800 \mathrm{rpm}$ \\
Isentropic velocity ratio, $U / C_{0}$ & 0.5 \\
Reaction rate, $\rho$ & 0.237 \\
Total-to-static pressure ratio, $\pi_{\mathrm{ts}}$ & 1.39 \\
Total-to-static efficiency, $\eta_{\mathrm{TS}}$ & 0.79 \\
\hline \hline \multicolumn{2}{c}{ CFD results: Nominal characteristics } \\
\hline \multicolumn{2}{c}{ Total-to-static pressure ratio, $\pi_{\mathrm{ts}}$} \\
Total-to-static efficiency, $\eta_{\mathrm{TS}}$ & 1.45 \\
\hline
\end{tabular}

for in the heritage data based on the original design estimates for these loss contributions. A good agreement between the original data and the simulation results has been obtained with respect to the pressure ratio and the efficiency, hence providing an empirical validation of the aforementioned loss models as well as of the CFD simulations. 


\section{120-KILONEWTON TURBOPUMP DESIGN}

The redesign experience, consecutive tool anchoring activities, and the planned test campaign with the heritage hardware all serve to establish the work flow for the Airbus DS GmbH turbopump design activities. This section details the current flow path design of the 120-kilonewton turbopump that shall establish a baseline for further optimization studies.

\subsection{Design Requirements and Configuration Trade-Off}

Based on the operating requirements (for the nominal conditions, see Table 3) for the 120-kilonewton turbopump, a dedicated trade-off has been performed (for details, see [1]) to define different configurations of the 120-kilonewton LOx-TPA, evaluating several alternatives to identify the most promising design variants. The selected baseline turbopump configuration consists of a radial diffuser pump with a high head inducer driven by a single stage subsonic axial turbine on the same shaft with a rotational speed of $25000 \mathrm{rpm}$.

Table 3 Required characteristics of 120-kilonewton turbopump

\begin{tabular}{lc}
\hline \multicolumn{1}{c}{ Parameter } & Value \\
\hline \multicolumn{1}{c}{ Pump requirements } \\
\hline Fluid & $\mathrm{LOx}$ \\
Nominal flow rate (at the outlet) & $22.8 \mathrm{~kg} / \mathrm{s}$ \\
Total pressure at the pump inlet & $3 \mathrm{bar}$ \\
Pump inlet temperature & $91.5 \mathrm{~K}$ \\
Pump outlet total pressure & $81.8 \mathrm{bar}$ \\
\hline \hline \multicolumn{2}{c}{ Turbine requirements } \\
\hline Fluid & $\mathrm{H}_{2}$ \\
Mass flow rate (including LOx-turbopump bypass) & $2.67 \mathrm{~kg} / \mathrm{s}$ \\
Bypass mass flow rate & $>20 \%$ \\
Total pressure at the inlet & $89 \mathrm{bar}$ \\
Inlet temperature & $218 \mathrm{~K}$ \\
Static pressure at the outlet & $75 \mathrm{bar}$ \\
\hline
\end{tabular}

\subsection{Pump Fluid Path Design}

Based on the nominal pump requirements and the selected rotational speed of $25000 \mathrm{rpm}$, a preliminary sizing was performed. The relevant nondimensional parameters are defined in Eq. (1). The first pump diameter and efficiency estimate were made based on the $N_{s}-D_{s}$-diagram [2]. In addition, an estimate 
of the minimum required shaft diameter was made. The number of blades $Z=6$ was based on the correlations from $[3,4]$. The suction characteristics of a pump stage without inducer were evaluated based on the Pfleiderer criterion [3]. This yields the first estimate of NPSHR, confirming indeed the need for an inducer. These estimates give the first idea of the overall dimensions of the pump and the requirements in terms of suction specific speed and inducer head.

Based on these predesign estimates, a preliminary design of the inducer was made. The inducer inlet was sized based on the Brumfield criterion to attain the minimal NPSHR value that provides sufficient cavitation margin. Following the approach from [5], an optimal flow coefficient of $\Phi_{\text {ind,in }}=0.1$ was selected, in line with the values for other realized LOx-inducers [2]. This is conservative in terms of the attained minimum experimental values specified in [5]. The inducer inlet hub-to-shroud ratio was determined based on a geometrical comparison with existing inducers (amongst others, the $\mathrm{H} 2 \mathrm{O}-\mathrm{LOx}$ inducer). The outlet hub-to-shroud ratio and the outlet angle were determined based on a parametric study, requiring that net positive suction head available (NPSHA) $>$ NPSHR at the impeller inlet with a margin that was anchored on existing hardware. As a baseline, the inducer outlet diameters at the hub and shroud and the impeller inlet diameters were fixed to the same value, verifying that the impeller suction diameter was close to the ideal value in terms of NPSHR. The blade number was set to $Z=3$ and the solidity were selected based on the recommendations from [5]. A sweep angle was selected for increased suction performance and to decrease the bending load on the 'corner flap' of the blade leading edge. The value for the tip clearance was based on the $\mathrm{H} 2 \mathrm{O}$ experience.

The shrouded impeller was designed to attain the required total head rise at a nominal head coefficient value of $\Psi_{\text {imp }}=0.85$ using semiempirical design functions and simultaneous anchoring on available reference data for existing pumps. The outlet blade height to impeller diameter ratio was set to yield a meridional deceleration close to unity. The axial extension of the impeller was sized according to Gülich [6]. The outlet angle was set in agreement with the recommendation from [4]. The blade mean lines were chosen such as to obtain a monotonous static pressure rise, while satisfying the Ackeret criterion for the relative velocity. The wrap angle was set to the maximum value that still enables manufacturing by means of milling.

The vaned diffuser was designed following recommendations from $[4,7-9]$ for the geometrical sizing of diameters, gaps, and clearances. The number of diffuser vanes was taken equal to the optimum value based on considerations of periodicity to avoid interaction with the impeller blades. The volute was designed for the maximum expected off-design flow with a circular cross section, folded inwards for compactness and flow stability. The cross-sectional area was determined using the Pfleiderer approach [3].

The resulting geometrical design (Fig. 6) and the design estimates for the nominal total and static pressure and the absolute velocity progressions through 
the pump (Fig. 7) are shown assuming a linear loss distribution between volute and diffusor (losses of both parts are not discriminated). The overall pump design is summarized in Table 4 .

A 3D CFD-analysis was made as a basis for further optimization loops. The computational grid encompasses the full 360 degree pump geometry and contains a total of $\sim 5.8$ million cells divided over 4 domains: 1.7 million for the inducer, 1.6 million for the impeller, 2.2 million for the diffuser, and 350000 for the volute. Concerning the inducer and impeller, a wall resolution with $y^{+}<300$ was applied.

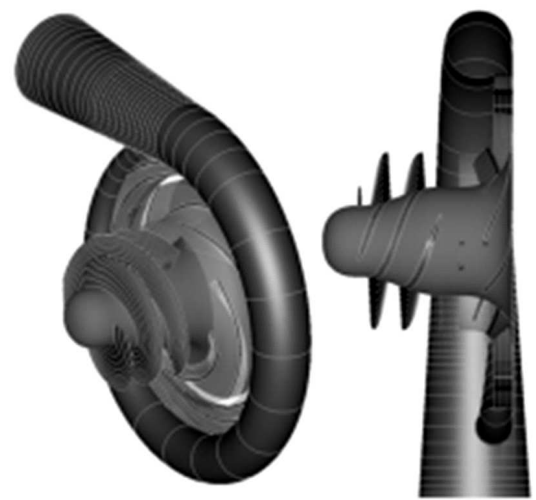

Figure 6 The 120-kilonewton LOx-pump design

Grid refinement studies on a single

channel model have shown that this approach is sufficient for the prediction of the head rise. The wall in the volute was treated with wall functions as a first approximation since the focus in the current investigation was on the characterization of the rotating parts.

Figure 8 shows the CFD result for the static pressure fields normalized by the total outlet pressure.

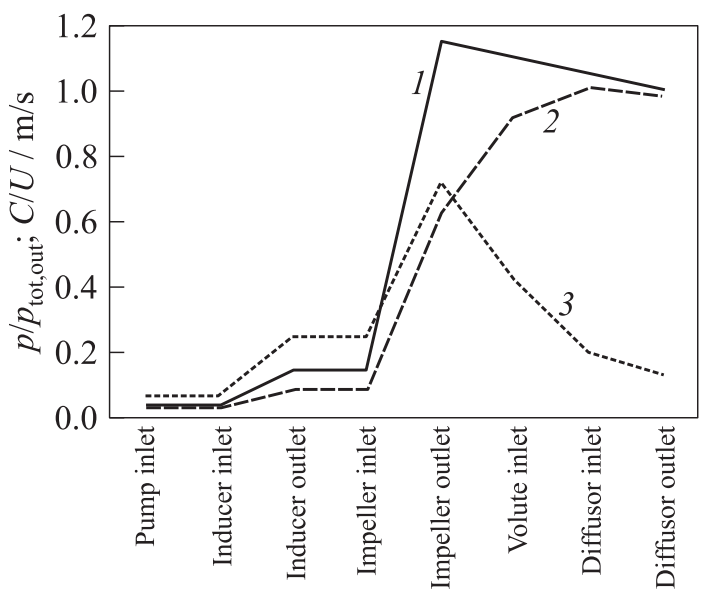

Figure 7 Estimated nominal progression of pressure (1 - total pressure; 2 - static pressure) and absolute velocity (3) 
Table 4 Pump design overview

\begin{tabular}{lc}
\hline \multicolumn{1}{c}{ Parameter } & Value \\
\hline \multicolumn{1}{c}{ Nominal pump characteristics } \\
\hline Rotation rate, $N$ & $25000 \mathrm{rpm}$ \\
Specific speed $(\mathrm{SI}), N_{s}$ & 25.9 \\
Design flow coefficient, $\Phi_{\text {pump }}$ & 0.09 \\
Design head coefficient, $\Psi_{\text {pump }}$ & 0.95 \\
Net positive suction head available, NPSHA & $17.0 \mathrm{~m}$ \\
Hydraulic efficiency, $\eta_{\text {hyd }}$ Nominal inducer characteristics & 0.80 \\
Pump overall efficiency, $\eta_{\text {tot }}$ & 0.68 \\
Shaft power, $P_{\text {shaft }}$ & $-236 \mathrm{~kW}$ \\
\hline \hline \multicolumn{2}{c}{} \\
\hline Design flow coefficient, inlet, $\Phi_{\text {ind,in }}$ & 0.10 \\
Design head coefficient, $\Psi_{\text {ind }}$ & 0.22 \\
Design suction specific speed, $N_{\mathrm{SS}}$ & 689 \\
Net positive suction head required, NPSHR & $9.6 \mathrm{~m}$ \\
Number of inducer blades, $Z_{\text {ind }}$ & 3 \\
Solidity, $\sigma$ & 2.8 \\
Hub/shroud ratio, inlet, $D_{h_{1}} / D_{s_{1}}$ & 0.4 \\
Hub/shroud ratio, outlet, $D_{h_{2}} / D_{s_{2}}$ & 0.6 \\
\hline \hline \multicolumn{2}{c}{ Nominal main impeller + diffusor characteristics } \\
\hline Design head coefficient, $\Psi_{\text {imp }}$ \\
Number of impeller blades, $Z_{\text {imp }}$ \\
Suction diameter/impeller diameter, $D_{s_{1}} / D_{2}$ \\
Number of diffusor blades, $Z_{\text {diff }}$ \\
Diffusor outlet diameter $/$ impeller diameter, $D_{4} / D_{2}$ \\
\hline
\end{tabular}

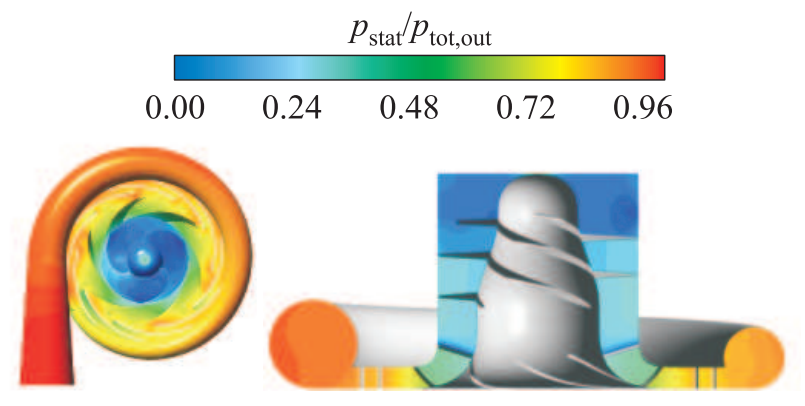

Figure 8 The 120-kilonewton LOx-pump nominal pressure iso-contours. 
The particle traces are visualized in Fig. 9 for several flow coefficient values.

Figure 10 shows the obtained off-design performance computed for several operating points (OPs), including a polynomial fit. The flow visualizations for the lower OPs show clear signs of flow breakdown, which is reflected in the efficiency. The nominal OP shows a regular flow behavior through the pump with a single vortex in the volute and the presence of a tip vortex at the inducer inlet. It is caused by an interaction between the main flow, the boundary layer at the casing, and the tip leakage flow due to a positive incidence of the flow on the inducer blade tip as has been explained in [10]. For flow rates superior to the foreseen application range, the inducer inlet tip vortex disappears whereas elevated velocities start to occur within the volute (as is to be expected since it operates outside its design range). The flow coefficient varies within approximately $\pm 10 \%$ from the nominal value for the foreseen operating envelope, which is where the maximum efficiency is obtained. The CFD predictions indicate a 5 percent higher hydraulic efficiency for the whole pump design than estimated in the preliminary design. The current design and simulation results provide the baseline for developing a physical understanding of the relevant flow phenomena as input for further optimization studies.

\subsection{Axial Turbine Flow Path Design}

The trade-off in [1] has identified a single stage impulse turbine (reaction rate $\rho$ $<0.15)$ as a viable option to produce the required shaft power for driving the $\mathrm{LOx}-$ pump while complying with the nominal operating conditions specified in Table 3 .

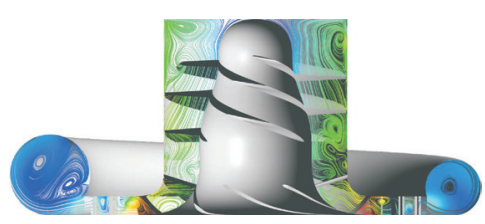

(a)

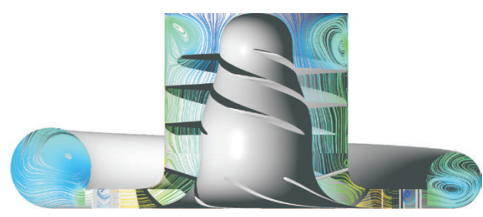

(b)

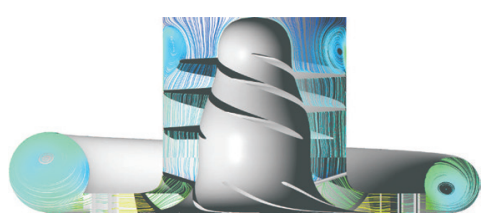

(c)

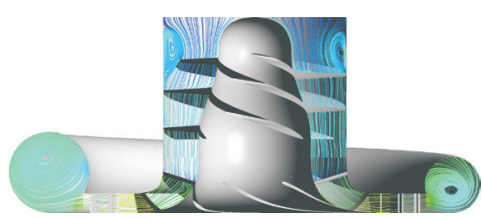

(d)

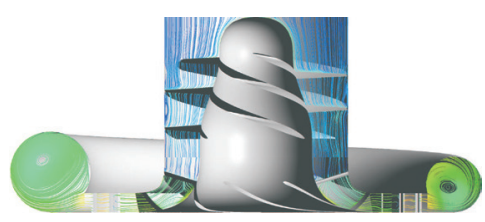

(e)

Figure 9 The 120-kilonewton LOx-pump off-design predictions for several flow coefficient values: $\quad\left(a \Phi / \Phi_{\text {nom }}=0.20\right.$; (b) 0.60 ; (c) 0.93 ; (d) 1.00 ; and (e) $\Phi / \Phi_{\text {nom }}=1.40$. 


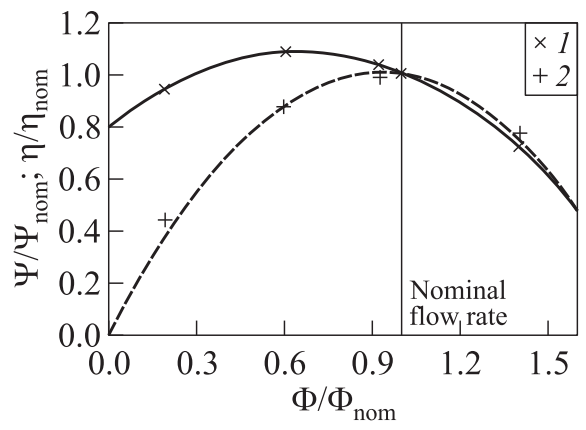

Figure 10 Off-design performance computed for several OPs: 1 - work coefficient; and 2 - efficiency

To start the design process, the turbine efficiency is a necessary input which determines, in particular, the rotor diameter and the combination of stator exit angle and blade height. The nominal characteristics in Table 3 with a 20 percent bypass mass flow rate directly prescribe a minimum overall efficiency level of $\eta=68 \%$ to attain the necessary power output; this is achievable based on the existing hardware values presented in [2].

The isentropic velocity ratio $U / C_{0}$ is taken as the governing parameter for the turbine efficiency, with the spouting velocity $C_{0}$ resulting from the input parameters. To make a detailed trade between efficiency $\eta_{\mathrm{TS}}$, stator exit angle $\alpha_{1}$, turbine disk diameter $D_{m}$, and rotor blade height $b_{r}$, the relation from [11] was evaluated in detail. Considering only the stator exit angles yielding the maximum efficiency (i.e., $10^{\circ}<\alpha_{1}<15^{\circ}$, defining all angles relative to the circumferential direction), the relation agrees well with the other theoretical and empirical relations that were considered in [4,11-15]. All curves attain a maximum efficiency $\eta_{\mathrm{TS}}$ between $79 \%$ and $84 \%$ with the optimal $U / C_{0}$ in the range of $0.40-0.55$ (Fig. 11), providing an indication of the required $U / C_{0}$.

The efficiency estimates for the current design case based on the correlation from [11] are shown in Fig. 12. The interdependence of the isentropic velocity ratio, the stator exit angle, and the rotor diameter and blade height is also shown. A stator exit angle of $\alpha_{1}=10^{\circ}$ at $U / C_{0}=0.4$ seems to offer the best compromise between efficiency and blade height for the first design, yielding a predicted efficiency of $\eta_{\mathrm{TS}}=81 \%$. This is sufficient for attaining an overall efficiency (ratio of shaft power to total-to-static isentropic power) of $\eta=68 \%$ based on the P111 heritage data, noting that the maximum for the total-tototal efficiency is very flat and the optimum efficiency value is also obtained close to $U / C_{0}=0.4$. Smaller values of $U / C_{0}$ would reduce the efficiency and, hence, potentially compromise the bypass mass flow rate requirement, and larger 


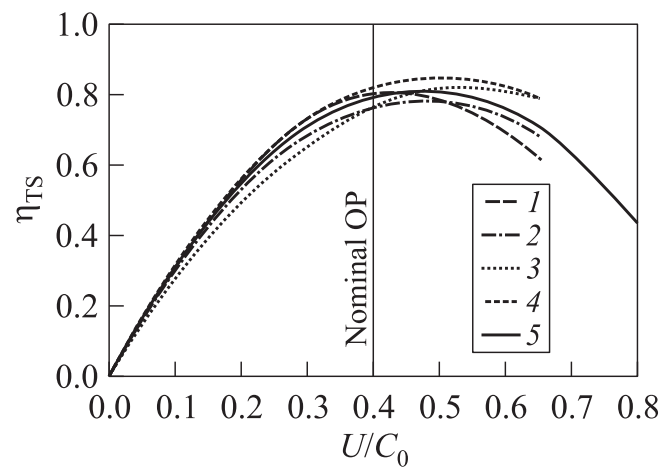

Figure 11 Total-to-static efficiency estimate correlations from literature: 1 - NASA SP8110 [14]; 2 - Nuzel and Huang [4]; 3 - Dobrovolskii [12]; 4 - Ovsyannikov and Borovskii [13]; and 5 - Glassman [15]
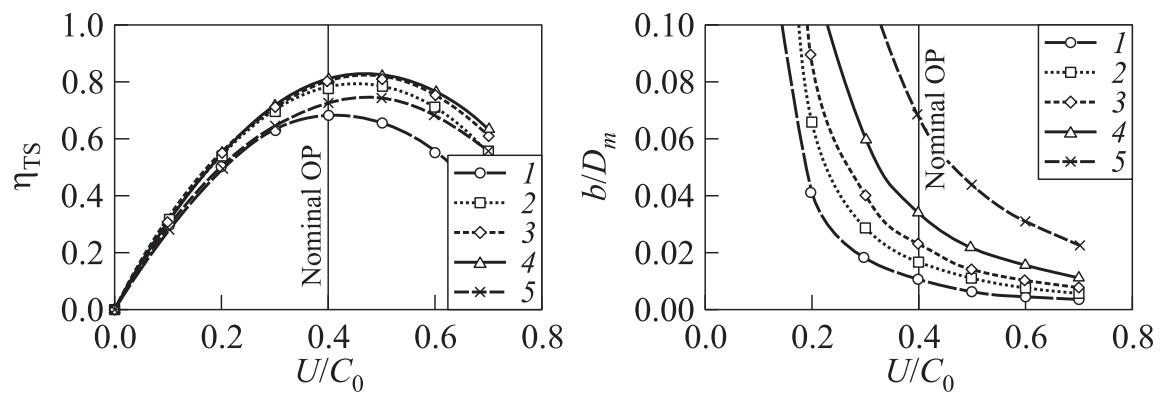

Figure 12 Optimization results for efficiency, rotor diameter, and blade height: 1 $\alpha_{1}=30^{\circ} ; 2-20^{\circ} ; 3-15^{\circ} ; 4-10^{\circ}$; and $5-\alpha_{1}=5^{\circ}$

values of $\alpha_{1}$ would progressively reduce the blade height, leading to unrealizably small blades. The basic blade height was taken constant for the whole length of the turbine (stator inlet, rotor inlet/outlet), with only a slight contraction at the stator outlet for guidance in order to avoid spillage due to expansion of the flow between stator outlet and rotor inlet, based on recommendations from [14].

Based on this preliminary sizing and providing the reaction rate of $\rho=0.15$ selected in the trade-off [1], the velocity triangles now follow directly from the 1D design. Using flow deviation values for the fluid leaving the stator blades based on [14], the required blade angles were estimated. The blade chord was calculated based on empirical correlations and a comparison to existing hardware. Finally, 
Table 5 Axial turbine design overview

\begin{tabular}{lc}
\hline \multicolumn{1}{c}{ Parameter } & Value \\
\hline \multicolumn{2}{c}{ Nominal turbine characteristics } \\
\hline Rotation rate, $N$ & $25000 \mathrm{rpm}$ \\
Isentropic velocity ratio, $U / C_{0}$ & 0.4 \\
Total-to-static pressure ratio, $\pi_{\mathrm{ts}}$ & 1.19 \\
Bypass mass flow rate percentage & $20 \%$ \\
Reaction rate, $\rho$ & 0.15 \\
Total-to-static efficiency, $\eta_{\mathrm{TS}}$ & 0.81 \\
Overall efficiency (minimal value), $\eta$ & 0.68 \\
Shaft power, $P_{\text {shaft }}$ Stator main dimensions \\
\hline \multicolumn{2}{c}{ Rotor main dimensions } \\
\hline Hub-to-shroud ratio, $D_{h} / D_{s}$ \\
Inlet flow angle (absolute), $\alpha_{0}$ \\
Outlet flow angle (absolute), $\alpha_{1}$ \\
Stagger angle, $\gamma_{s}$ \\
Number of blades, $Z_{s}$ \\
\hline \multicolumn{2}{c}{ Ro.936 } \\
\hline \hline Hub-to-shroud ratio, $D_{h} / D_{s}$ & $90^{\circ}$ \\
Inlet flow angle (relative), $\beta_{1}$ & $10^{\circ}$ \\
Outlet flow angle (relative), $\beta_{2}$ & $30^{\circ}$ \\
Stagger angle, $\gamma_{r}$ & 0.933 \\
Number of blades, $Z_{r}$ & $20^{\circ}$ \\
\hline
\end{tabular}

the blade design was generated starting from available standard profiles, using the respective recommended values for pitch and stagger angle for the selected profiles. The final blade profile was generated by means of Bezier curves, using optimization loops with CFD predictions to attain the desired hydraulic power output of the turbine. The overall axial turbine design is summarized in Table 5. The blade and meridional design are shown in Fig. 13, together with the velocity triangles (values are normalized by the blade speed $U$ ) and the progression of the flow quantities through the turbine (the stations represent the stator inlet $(0)$, stator outlet/rotor inlet (1), and rotor outlet (2), respectively).

In view of the inlet and outlet design for the turbine, a trade was made with respect to the flow direction. A configuration with inlet manifold and axial outlet was compared with a configuration with axial inlet and outlet volute. The latter configuration has been selected as a baseline because it provides an axial inflow to the turbine stator and it has the potential of minimizing losses at the turbine outlet by reabsorption of the residual swirl component.

Figure 14 shows the geometry with the applied numerical mesh for the 3D CFD simulations as well as representative results of these turbine simulations. 


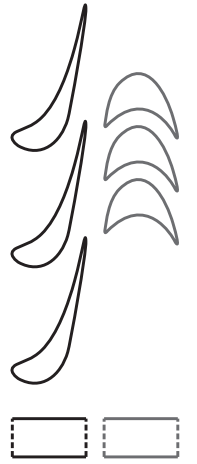

(a)

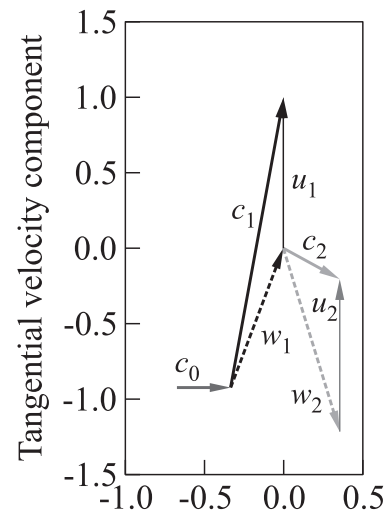

Meridional velocity component

(b)

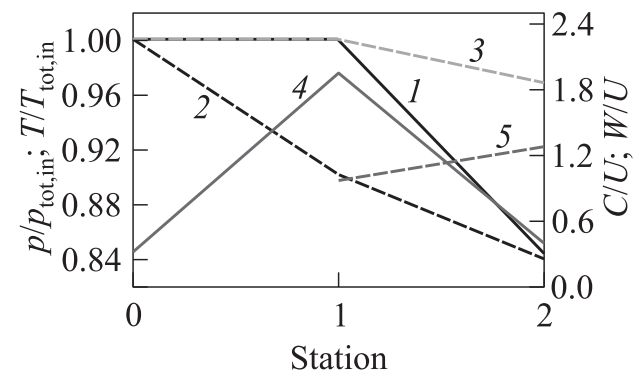

(c)

Figure 13 Blade and meridional design $(a)$, velocity triangles normalized by the rotor speed $U(b)$, and normalized flow quantities progression $(c): 1$ - total pressure; 2 - static pressure; 3 - total temperature; 4 - total absolute velocity; and 5 total relative velocity

The computational grid has a total size of $\sim 1.3$ million cells. It is divided into two domains: the stator domain with 1.0 million cells and the rotor domain with 300000 cells, both resolving a single blade. The applied wall resolution is $y^{+}=100$ using wall functions. The appropriate periodic boundary conditions were used to represent the complete turbine behavior. Concerning the CFD results, Fig. $14 b$ depicts the static pressure field normalized by the total inlet pressure and Fig. 14c displays the relative Mach field. Shown are for both fields a blade-to-blade view generated at a relative blade span of 0.5 (top figures) and a mass weighted meridional view (bottom figures). The required power level and the efficiency were surpassed by a few percent in the last design iteration. This desired stator exit angle was $1^{\circ}$ smaller than the design value, whereas 


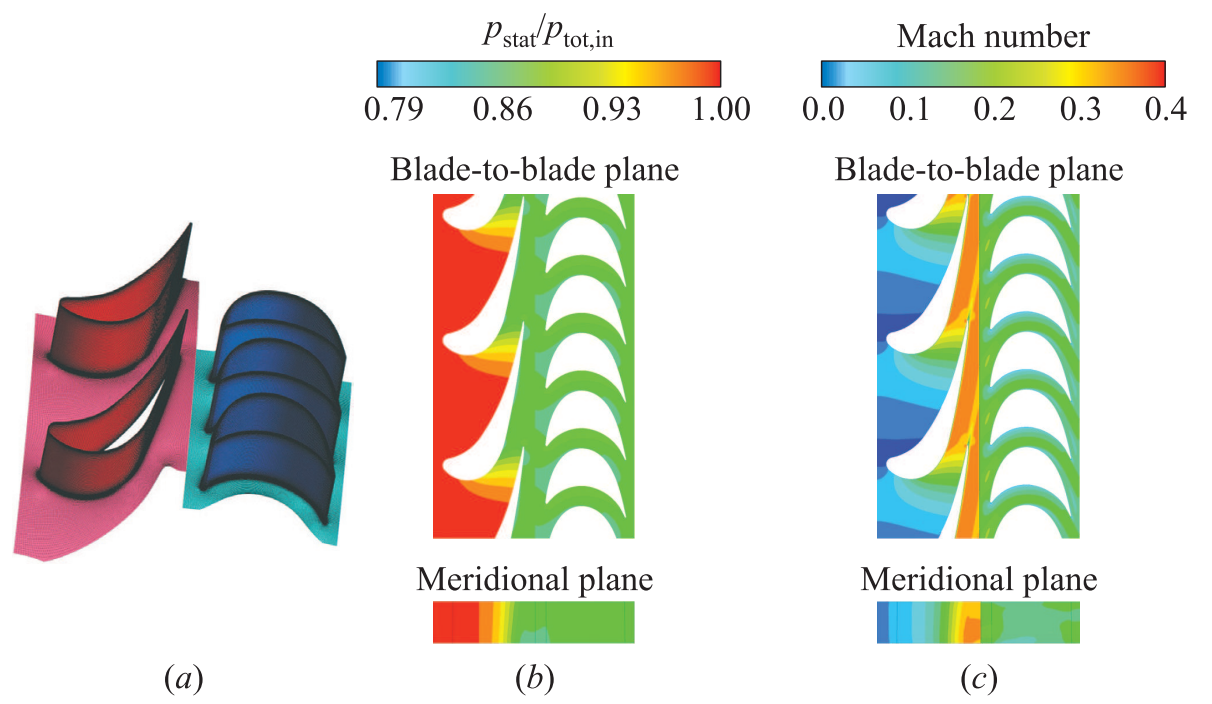

Figure 14 The 3D CFD results for the 120-kilonewton axial turbine: (a) numerical simulation mesh; $(b)$ pressure ratio; and $(c)$ relative Mach number

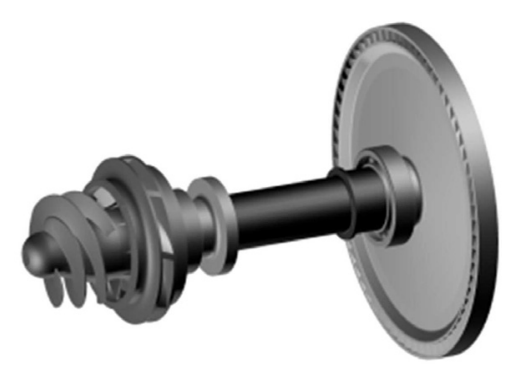

(a)

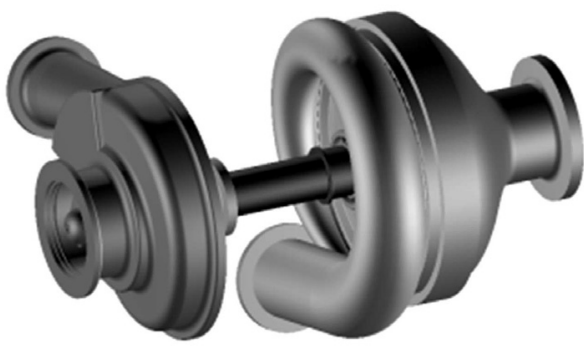

(b)

Figure 15 Three-dimensional CAD view of the 120-kilonewton turbopump design: (a) rotating parts; and (b) flow path including in/outlets

the flow turning $180^{\circ}-\beta_{F_{2}}-\beta_{F_{1}}$ was attained to within less than half a degree. The current design and simulation results provide the baseline for developing a physical understanding of the flow phenomena as input for further optimization studies.

To summarize the fluidic design, Fig. 15 shows the 3D CAD view of the rotating parts of the 120-kilonewton turbopump design including all principal fluidic parts (inlets/outlets, volutes, and diffusers). 


\section{120-KILONEWTON TEST ACTIVITIES}

Inducer characterization tests in water have been performed at the Von Karman Institute of Fluid Dynamics (VKI) in the frame of an Airbus DS funded activity. The scaling to attain the proper test conditions is shown in Table 6 . The inducer has geometrically been scaled up to fit the test section and manufactured from a polymeric material (acrylonitrile butadiene styrene, ABS) by means of rapid prototyping (Fig. 16). The hub contour has been extended to accommodate the larger test bench interface diameter. The rotation speed and flow rate have been scaled based on flow coefficient and head coefficient similarity, verifying that the Reynolds number is sufficiently high to attain similarity of the inducer performance. In addition, the water is heated to the appropriate temperature to attain thermal similarity with LOx based on the thermal effect parameter $\Sigma^{*}[8]$.

The tests will be evaluated to confirm the inducer characteristics, both in terms of achieved head coefficient and attained suction performance. In ad-

Table 6 Scaling for water tests

\begin{tabular}{lcc}
\hline \multicolumn{1}{c}{ Parameter } & LOx & Water \\
\hline Inlet temperature, $T_{\text {in }}, \mathrm{K}$ & 91.5 & 338.7 \\
Rotation rate, $N$, rpm & 25000 & 1500 \\
Geometrical scale & $1: 1$ & $1.3: 1$ \\
Flow coefficient, $\Phi_{\text {ind,in }}$ & 0.10 & 0.10 \\
Head coefficient, $\Psi_{\text {ind }}$ & 0.22 & 0.22 \\
Thermal effect parameter, $\Sigma^{*}$ & 73.6 & 73.6 \\
NPSHR, m & 9.6 & 0.054 \\
Suction specific speed, $N_{\text {SS }}$ & 689 & 689 \\
\hline
\end{tabular}

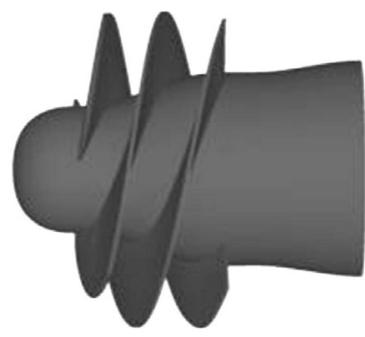

(a)

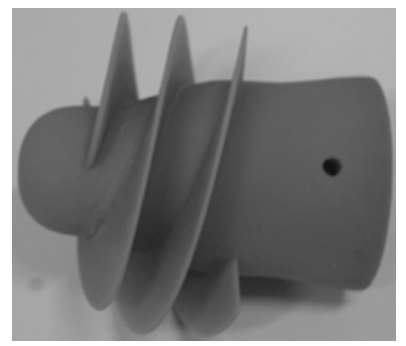

(b)

Figure 16 The 120-kilonewton LOx-inducer design (a) compared to rapid prototyping test hardware $(b)$ 

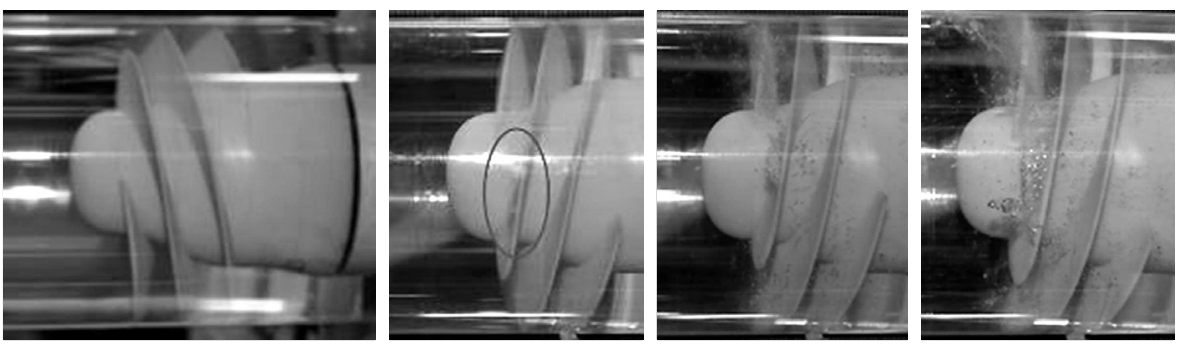

Figure 17 The 120-kilonewton LOx-inducer during cavitation testing at the VKI

dition, the dynamic cavitation behavior will be characterized. The first cavitation visualization results are shown in Fig. 17, starting from the nominal conditions on the left down to a cavitation coefficient of $\sigma=0.25$ on the right. The first occurrence of cavitation is highlighted by the ellipse. The test campaign results shall serve as input for the validation of the design tools, the CFD simulations, and cavitation models as a baseline for further inducer optimizations.

\section{CONCLUDING REMARKS}

Within the context of the German nationally funded research programme "TARES," several activities have been initiated to build up and reestablish turbopump design competences within Airbus DS GmbH. The main focus has firstly been on the anchoring of the fluidic design and simulation tools on in-house heritage hardware; subsequently, a design was made of an LOx turbopump for a 120-kilonewton thrust class expander cycle rocket engine, including accompanying experimental and modeling efforts. These activities have served to attain the following milestones:

- reestablishing proven design heritage based on the $\mathrm{H} 2 \mathrm{O} 200$-kilonewton and the P111 50-kilonewton staged combustion engine turbopump hardware;

- anchoring of the turbopump fluidic design tools to the heritage hardware and available literature data for existing turbopumps;

- generating a 120-kilonewton LOx-turbopump design including all main flow path components;

- performing 3D CFD simulations of the heritage hardware and the 120kilonewton turbopump design; and 
- obtaining first cavitation test results in water of the 120-kilonewton LOxinducer design.

Further activities have been performed, such as the hydraulic characterization campaign for the heritage $\mathrm{H} 2 \mathrm{O}$ LOx-inducer. The combined experimental results provide validation data for $3 \mathrm{D}$ CFD simulations and cavitation modeling.

These milestones serve to establish the Airbus DS GmbH fluidic design process and have provided a baseline turbopump design for further optimizations, experimental investigations, and modeling studies.

\section{ACKNOWLEDGMENTS}

This work was performed within the national technology program TARES. This program is sponsored by the German Space Agency, DLR Bonn, under Contract No.50RL1210. This support is gratefully acknowledged here. In addition, the effective cooperation with the Von Karman Institute for Fluid Dynamics (VKI) is gratefully acknowledged.

\section{REFERENCES}

1. Maeding, C., L. Souverein, D. Hummel, S. Koenigbauer, A. Wagner, and J. Alting. 2015. A preliminary design study for an expander LOx turbopump. 6th European Conference for Aeronautics and Space Sciences Proceedings. Krakow, Poland.

2. Schmidt, G. 1999. Technik der Flüssigkeits-Raketentriebwerke. DaimlerChrysler Aerospace.

3. Pfleiderer, C. 1955. Die Kreiselpumpen für Flüssigkeiten und Gase. 4th ed. Springer. $542 \mathrm{p}$.

4. Huzel, D. K., and D. H. Huang. 1992. Modern engineering for design of liquidpropellant rocket engines. AIAA progress in aeronautics. Washington, D.C. Vol. 147. 431 p.

5. Jakobsen, R. B. 1971. Liquid rocket engine turbopump inducers. NASA SP8052.

6. Gülich, J.F. 2010. Kreiselpumpen-Handbuch für Entwicklung, Anlagenplanung und Betrieb. 3rd ed. Springer. 1020 p.

7. Furst, J. K. 1973. Liquid rocket engine centrifugal flow turbopumps. NASA SP8109.

8. Brennen, C. E. 1994. Hydrodynamics of pumps. White River, UT: Concepts NREC. $300 \mathrm{p}$.

9. Guinzburg, A., M. Williams, and T. Ferguson. 2002. Deep throttle turbopump technology design concepts. JANNAF. Destin, FL.

10. Arnone, A., P. Boncinelli, A. Munari, and E. Spano. 1999. Application of CFD techniques to the design of the Ariane 5 turbopump. AIAA Paper No. 99-3380. 
11. Glassman, A. J. 1992. Computer code for preliminary sizing analysis of axial-flow turbines. NASA CR-4430.

12. Dobrovolskii, M. V. 1968. Zhidkostnye raketnye dvigateli [Liquid fuel rocket engines]. Moscow: Mashinostroenie. 398 p.

13. Ovsyannikov, B. V., and B. I. Borovskii. 1971. Teoriya i raschet agregatov pitaniya zhidkostnykh raketnykh dvigateley [Theory and analysis of the power-supply units of the liquid fuel rocket engines]. Moscow: Mashinostroenie. $540 \mathrm{p}$.

14. Douglas, H.W. 1974. Liquid rocket engine turbines. NASA SP-8110.

15. Glassman, A. J. 1994. Turbine design and application. NASA SP-290. 